\title{
Indiana community health workers: challenges and opportunities for workforce development
}

\author{
Natalia M. Rodriguez', Yumary Ruiz' ${ }^{1}$ Ashley H. Meredith², Carlyn Kimiecik' , Omolola A. Adeoye-Olatunde², \\ Lynnet Francesca Kimera ${ }^{2}$ and Jasmine D. Gonzalvo ${ }^{2^{*}}$
}

\begin{abstract}
Background: An interest in, and the need for, Community Health Workers (CHWs) in the United States is growing exponentially. CHWs possess a unique ability to relate to and build trust with communities in order to improve clinical outcomes, while building individual and community capacity. Given their critical role in addressing social determinants of health, expanding the CHW workforce is crucial. However, creating CHW jobs, facilitating training and certifcation, and establishing sustainable financing models to support this workforce has been challenging.

Methods: A mixed-methods study consisting of an online survey and focus group discussions assessed the strengths, practices, and challenges to CHW workforce sustainability and expansion in the state of Indiana, including perspectives from both CHWs and employers.

Results: Across 8 topics, mixed data analysis revealed 28 findings that were both complementary and unique across focus group and survey results. Results highlighted CHW skills and attributes, illustrated the recruitment and hiring process, and provided insight into measuring outcomes and outputs. Findings also indicated a need to build position validation, professional development, and billing and reimbursement capacity.

Conclusion: Building and sustaining the CHW workforce will require creating an evidence base of roles and impact, increasing awareness of existing reimbursement mechanisms, and sharing best practices across employer organizations to promote optimal recruitment, training, supervision, career development, and funding strategies.
\end{abstract}

Keywords: Community health workers, Capacity building, Workforce, Indiana

\section{Background}

As frontline public health workers, community health workers (CHWs) are trusted community members who have a close understanding of the community they serve [1]. This position of trust enables CHWs to serve as an essential link between health and social services and communities earning lower incomes who have been

\footnotetext{
*Correspondence: jgonzalv@purdue.edu

${ }^{2}$ College of Pharmacy, Department of Pharmacy Practice, Purdue

University Center for Health Equity and Innovation, 640 Eskenazi Ave, Fifth

Third Bank FOB, 3rd Floor, Indianapolis, IN 46202, USA

Full list of author information is available at the end of the article
}

historically marginalized to facilitate access and improve the quality and cultural competence of service delivery [2]. CHWs improve clinical outcomes and build individual and community capacity by increasing health knowledge and self-sufficiency through a range of activities, such as outreach, community education, informal counseling, social support, advocacy, and community-based research and evaluation [2]. Kangovi and colleagues [3] reported a $28 \%$ reduction in hospitalizations following a $\mathrm{CHW}$ intervention in a population earning lower incomes with multiple chronic conditions. Ingram et al. [4] found CHWs significantly improved clinical markers 
(i.e., glycosylated hemoglobin, body mass index, and total cholesterol) of people living with chronic diseases. Furthermore, CHWs have been shown to save state Medicaid programs $\$ 4200$ per beneficiary [5], and if scaled to even a quarter of United States (US) Medicaid beneficiaries, studies show CHWs would save taxpayers $\$ 78$ billion annually [5].

Given CHWs' critical role in addressing social determinants of health, including overcoming barriers to employment and financial self-sufficiency, expanding the $\mathrm{CHW}$ workforce is a powerful way to catalyze economic self-sufficiency in neighborhoods with incomes below the federal poverty levels. However, creating $\mathrm{CHW}$ jobs, facilitating training and certification, and establishing mechanisms to sustain this growing workforce has been challenging. Recently, Cacal [6] found that only 21 states in the US had legislative bills addressing CHWs and only 15 states had formalized definitions of CHWs. Establishing standardized definitions of CHWs is vital to reaching a consensus regarding CHW training, certification, and workforce development. Many states have modified the American Public Health Association (APHA) definition to enhance relevance in their communities (e.g., use of the word promotora [a lay health worker that works in a Spanish-speaking community]), which contributes to lack of clarity regarding $\mathrm{CHW}$ roles and titles [6]. In addition to a lack of a standard definition, there is no national consensus on $\mathrm{CHW}$ certification. A National Academy for State Health Policy (NASHP) survey reported only 17 states have certification pathways for CHWs. Certification is often voluntary but sometimes necessary for Medicare reimbursement [7].

In Indiana, sustaining $\mathrm{CHW}$ positions has been challenging due to limited funding and lack of infrastructure that fosters workforce growth and expansion. This has been due in part to poor awareness of CHWs and their roles, cost prohibitive training and certification opportunities for populations earning low incomes, and an underutilized and complex reimbursement system through Indiana Health Coverage Programs that fails to include a full range of CHW services. Despite these challenges, the employment of CHWs in Indiana is projected to grow at a rate of $14 \%$ from 2018 to 2028 . With approximately $220 \mathrm{CHW}$ job openings annually, this demonstrates a much faster rate of growth than the average for all occupations [8] and is associated with average annual earnings of $\$ 38,050$ [9]. $\mathrm{CHW}$ certification in Indiana is open to anyone aged $\geq 18$ years with a high school diploma or equivalent, creating a promising employment pathway for young people and those without higher education, particularly for groups that have been marginalized $[10,11]$. To promote the unification of CHWs, the Indiana Community Health Worker
Association (INCHWA) has developed a framework through which Indiana CHWs may become certified. Working with the Indiana Department of Health, INCHWA approves "training vendors" certified by the state to train and produce Medicaid reimbursable certified community health workers. While certification is not a requirement to practice as a $\mathrm{CHW}$ in Indiana, it is required to receive reimbursement from Medicaid.

CHWDI was created in 2020 in recognition of the immensely important role and expected growth of CHWs, and to address CHW workforce development challenges in Indiana. Dedicated to health equity, CHWDI's mission is to expand the Indiana CHW workforce to increase access to health and social services for under-resourced communities while also increasing employment opportunities for community members. Thus, to inform CHWDI's statewide initiatives in Indiana, the objectives of this study were to conduct a statewide needs assessment to 1) characterize the current $\mathrm{CHW}$ workforce landscape, 2) describe $\mathrm{CHWs}$ experiences with training, certification, scopes of work, job security, career development opportunities, and community priorities, and 3) explore employers experiences in hiring, training, and supervising CHWs, current challenges and potential areas of needed training and development activities, and funding mechanisms to sustain or expand CHW employment opportunities.

\section{Methods}

Utilizing a concurrent, multimethod approach [12], all aspects of this study, including the initial design, were informed though diverse stakeholder engagement. Specifically, in collaboration with INCHWA, a steering committee was established which included 25 members from public health and social service government agencies, academic institutions, and other key community stakeholders. The steering committee was convened to provide essential insight that will continuously inform the implementation, evaluation, and long-term sustainability of the institute's efforts. This study was approved by the Purdue University Institutional Review Board (IRB; protocol IRB 2020-1468) and the review deemed this study exempt. Informed consent was obtained verbally by all participants prior to commencing research activities as approved by Purdue University's IRB.

\section{Data collection instrument development}

The research team and steering committee collaborated to identify objectives pertaining to data collection instrument development (i.e., survey, focus group questionnaire). Both quantitative and qualitative data collection 
instruments were framed by 13 pre-defined overarching topics (see Appendix).

\section{Quantitative instrument development}

An initial survey was created by the research team, with feedback from the steering committee and INCHWA to ensure appropriate content and consistent language leading to minor modifications (e.g., providing additional response options and language clarity for intended audience and adding questions for additional contact-related information from participants) and four items added. The final 59-item survey sought to establish a demographic profile of Indiana $\mathrm{CHWs}$, identifying $\mathrm{CHW}$ job titles, roles, employment sectors, and activities, as well as to capture CHW certification and training prevalence, and collect demographic information of communities and populations that Indiana CHWs serve.

\section{Qualitative instrument development}

Concurrent with survey development, focus group data collection instruments followed a similar process as that of the survey. With the goals of receiving $\mathrm{CHW}$ and employer input related to the $\mathrm{CHW}$ workforce and gaining a greater understanding of strengths and challenges of the workforce and $\mathrm{CHW}$ roles, two semi-structured focus group guides (Appendix) were developed. Specifically, one guide was developed for CHWs and a separate guide for employers of CHWs.

\section{Quantitative data collection and analysis}

In November 2020, an online survey of Indiana CHWs was conducted through use of an anonymous Qualtrics survey link distributed through INCHWA. Respondents could forward the link to additional CHWs. The survey remained open for 4 weeks. Only $\mathrm{CHW}$ respondents that indicated that they were based in Indiana were included in data analysis. Additionally, to eliminate potentially duplicative and fraudulent responses, researchers excluded responses from identical internet protocol (IP) addresses and email stems, that took 5 minutes or less to complete (minimum survey completion time of $10 \mathrm{~min}$ based on the estimated time to complete the survey), and that were less than 50\% complete. SPSS software (Version 26) was used to descriptively analyze data (i.e., frequencies, counts). All eligible survey participants received a $\$ 10$ e-gift card.

\section{Qualitative data collection and analysis}

Focus group participants were recruited through INCHWA's mailing lists, with all interested participants able to engage via Zoom videoconferencing software. Focus groups were facilitated by members of the research team over a four-week period in November-December 2020, with each focus group lasting between 75 and $105 \mathrm{~min}$. All participants received a $\$ 45$ e-gift card as compensation for their time. All focus groups were recorded verbatim and transcribed using Otter.ai software. Research assistants completed a quality check of each transcript to ensure accuracy prior to data analysis.

NVivo 12, a qualitative software, [13] was used to deductively and inductively analyze data to identify emergent topics $[14,15]$. First, using the focus group guide a codebook with 13 pre-defined topics was developed and deductive coding was carried out. Next, an inductive analysis was conducted to further refine the pre-defined topics as well as add new topics to the qualitative codebook $[15,16]$. Throughout the deductive and inductive analysis, coding consisted of identifying direct quotes that represented each topic and organizing these quotes, or raw data, into findings by topic while succinctly combining quotes into broader topics [6, 14]. Researchers met to review and discuss findings and any discrepancies were resolved through discussion [17].

\section{Mixed data analysis}

To identify areas of concordance among data sources, survey and focus group data were triangulated using a data consolidation analytic approach [18, 19]. This approach blends qualitative and quantitative data to investigate a phenomenon, thus corroborating internal validity of findings [20]. Microsoft Word and Nvivo $12^{\circledR}[13]$ software were used to compare and consolidate findings via cross-tabulation of quantitative and qualitative findings by each of the pre-defined and inductively derived topics.

\section{Results}

A total of 1804 survey responses were received with 1156 responses excluded due to not meeting inclusion criteria (see Methods section). A total of 648 responses were eligible for analysis. See Table 1 for demographics of survey respondents. Four total focus groups were conducted with participants representing 25 different organizations throughout Indiana. Two focus groups were conducted with CHWs $(N=7$ and $N=7)$ and two with employers $(N=9$ and $N=7)$. Across 8 topics, mixed data analysis of survey results and focus groups revealed 28 findings (Table 2). Overall, 6 (21\%) findings were complementary and supported by both quantitative and qualitative data sets, $20(71 \%)$ findings were unique to focus group results, and 2 (7\%) findings were unique to survey results. There was no observed divergence of results between the two data sources (Table 2). The 8 topics are detailed 
Table 1 Survey Participant Demographics

\begin{tabular}{|c|c|}
\hline Variable & No. (\%) \\
\hline \multicolumn{2}{|l|}{$\operatorname{Sex}(N=648)$} \\
\hline Male & $364(56)$ \\
\hline Female & $280(43)$ \\
\hline Did not respond & $4(1)$ \\
\hline \multicolumn{2}{|l|}{ Race/Ethnicity $(\mathrm{N}=648)$} \\
\hline White & $439(68)^{*}$ \\
\hline Black or African American & $61(9)$ \\
\hline Asian & $19(3)$ \\
\hline Hispanic or Latino & $29(5)$ \\
\hline Native Hawaiian or Pacific Islander & $4(1)$ \\
\hline Two or More Races & $89(14)$ \\
\hline \multicolumn{2}{|l|}{ Education Level $(\mathrm{N}=648)$} \\
\hline Less than high school & $11(2)$ \\
\hline High school or GED equivalent & $92(14)$ \\
\hline Technical school/Some college or associates degree & $288(44)$ \\
\hline Bachelor degree & $157(24)$ \\
\hline Graduate degree or higher & $92(14)$ \\
\hline Did not respond & $8(1)$ \\
\hline \multicolumn{2}{|l|}{ Currently a certified CHW in Indiana $(\mathrm{N}=648)$} \\
\hline Yes & $526(81)$ \\
\hline No & $65(10)$ \\
\hline No, but interested & $29(5)$ \\
\hline Waiting for training certification, or testing results & $10(2)$ \\
\hline Unsure & $17(3)$ \\
\hline Did not respond & $1(0.2)$ \\
\hline \multicolumn{2}{|c|}{ Current/past employer paid for CHW certification $(n=526)$} \\
\hline Yes & $492(94)$ \\
\hline No & $34(6)$ \\
\hline \multicolumn{2}{|l|}{ Obtained CHW certification in Indiana $(n=526)$} \\
\hline Yes & $517(98)$ \\
\hline No & $9(2)$ \\
\hline \multicolumn{2}{|l|}{ Provide CHW services as paid staff or volunteer $(\mathrm{N}=648)$} \\
\hline Paid Staff & $516(79)$ \\
\hline Volunteer & $128(20)$ \\
\hline Did not respond & $4(1)$ \\
\hline \multicolumn{2}{|l|}{ Current hourly CHW wage $(\mathrm{N}=648)$} \\
\hline More than zero and up to $\$ 7.25$ & $135(21)$ \\
\hline More than $\$ 7.25$ and up to $\$ 14$ & $247(38)$ \\
\hline More than $\$ 14$ and up to $\$ 18$ & $187(29)$ \\
\hline More than $\$ 18$ & $56(9)$ \\
\hline 0 (unpaid) & $22(3)$ \\
\hline Did not respond & $1(0.2)$ \\
\hline \multicolumn{2}{|l|}{ Provide CHW services full-time or part-time $(\mathrm{N}=648)$} \\
\hline Full-time & $561(87)$ \\
\hline Part-time & $78(12)$ \\
\hline Did not respond & $9(1)$ \\
\hline \multicolumn{2}{|l|}{ Number of part-time hours per week $(n=78)$} \\
\hline $10 \mathrm{~h}$ or less & $18(23)$ \\
\hline $11-20 h$ & $40(51)$ \\
\hline
\end{tabular}

Table 1 (continued)

\begin{tabular}{ll}
\hline Variable & No. (\%) \\
\hline 20h or more & $15(19)$ \\
\hline Did not respond & $5(7)$ \\
Length serving at current organization $(\mathbf{N}=\mathbf{6 4 8})$ & \\
Less than a year & $39(6)$ \\
$1-5$ years & $316(48)$ \\
$6-10$ years & $248(38)$ \\
$11-15$ years & $34(5)$ \\
$16-20 y e a r s$ & $5(1)$ \\
Over 20years & $4(1)$ \\
Did not respond & $2(1)$ \\
\hline
\end{tabular}

below with both quantitative (survey) and qualitative (focus groups) results presented within the respected topic.

\section{Topic 1: who are community health workers?}

Quantitative analysis of survey results revealed that Indiana CHWs are highly diverse with 43 countries and 14 languages represented (Table 1). CHWs are employed under various titles (Table 3 ) and in various employment sectors and settings, including Social and Community Services (24\%), County Health Departments (15\%), and Private health sectors (13\%) (Table 4). CHW services are provided throughout Indiana's 92 counties and triangulated data supported existing literature [21, 22] that CHWs serve clients who face a myriad of economic, social, physical, and environmental challenges (Tables 2 and 5).

\section{Topic 2: attributes, roles, and responsibilities}

CHWs and employers both described key CHW attributes, characteristics, roles, and responsibilities, six of which aligned with the national CHW Core Consensus (C3) Project, which aims to increase visibility and a greater understanding of CHWs [23]. Following a post-hoc qualitative analysis, these nationally recognized C3 qualities, roles, and skills were mapped to our Topic 2 findings in Table 2. CHWs are often motivated by their "want to work with a lot of people [from] different backgrounds" and from the community they serve, or they leverage their own lived experience to connect and relate with clients. CHWs view themselves as trusted members of the community who actively work to create and keep this trust, "...it's usually just a matter of them [clients] getting to know and trust you." CHWs acknowledged that trust could be difficult to build but described qualities they possess that allow them to effectively 


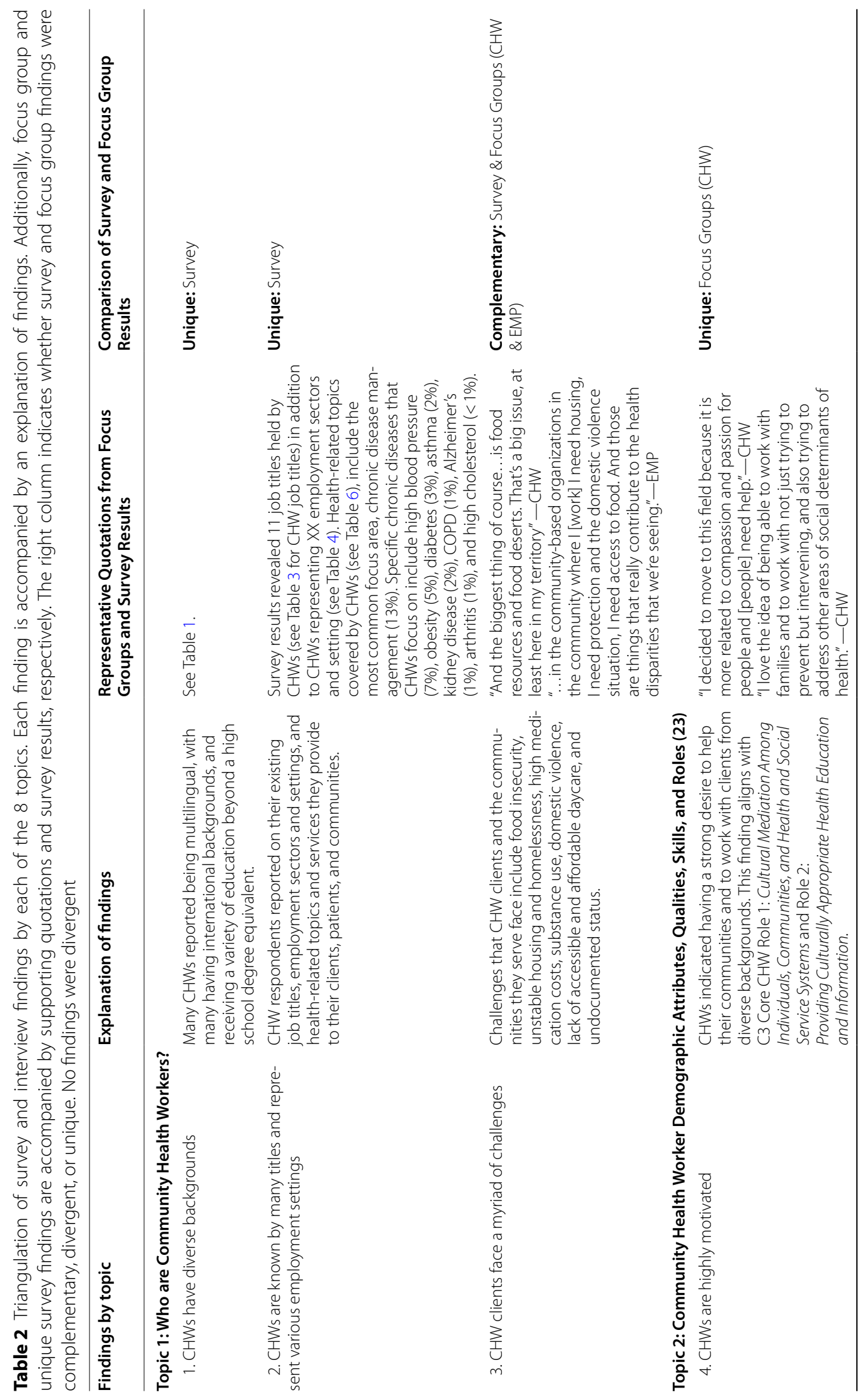




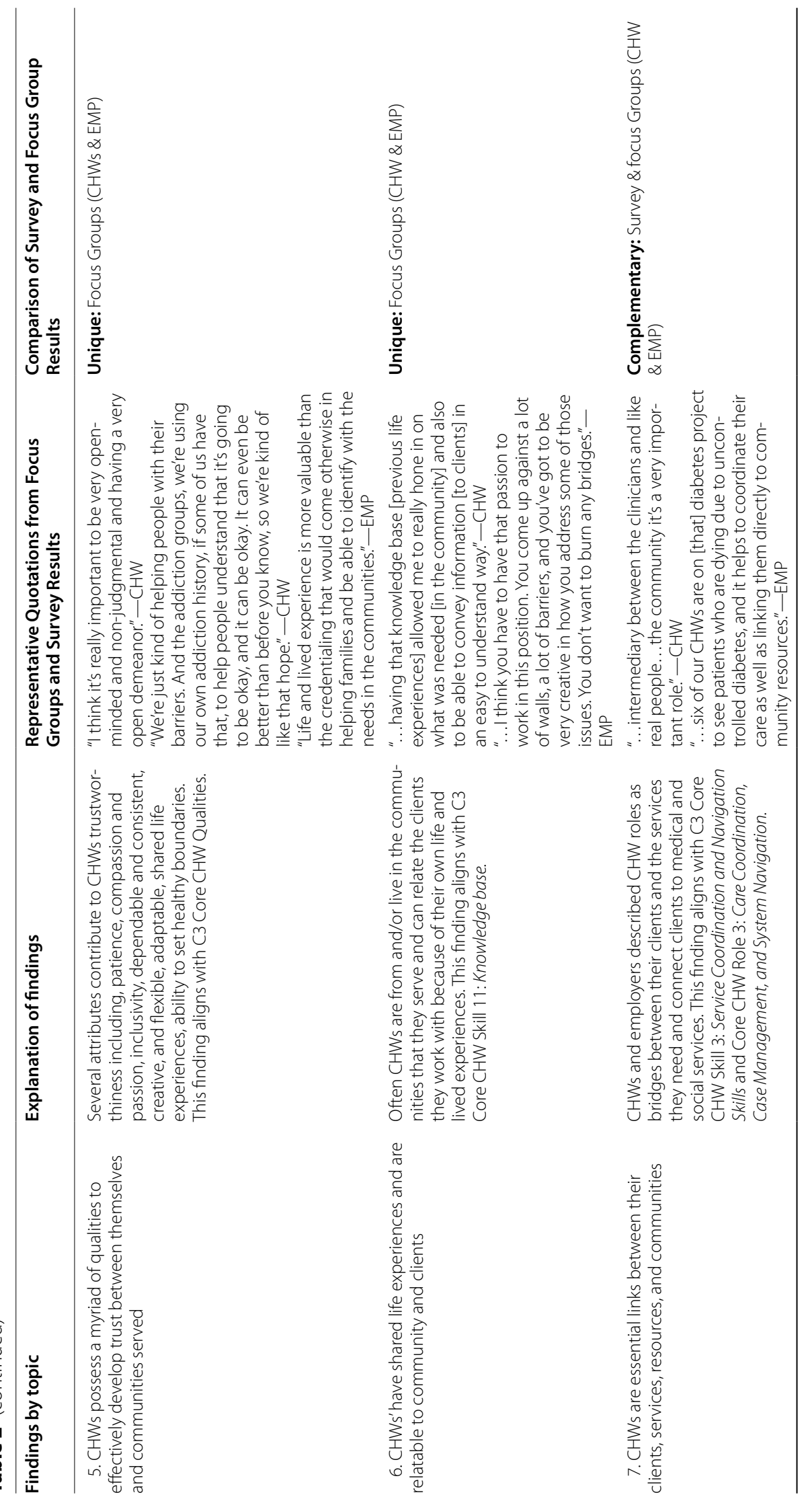




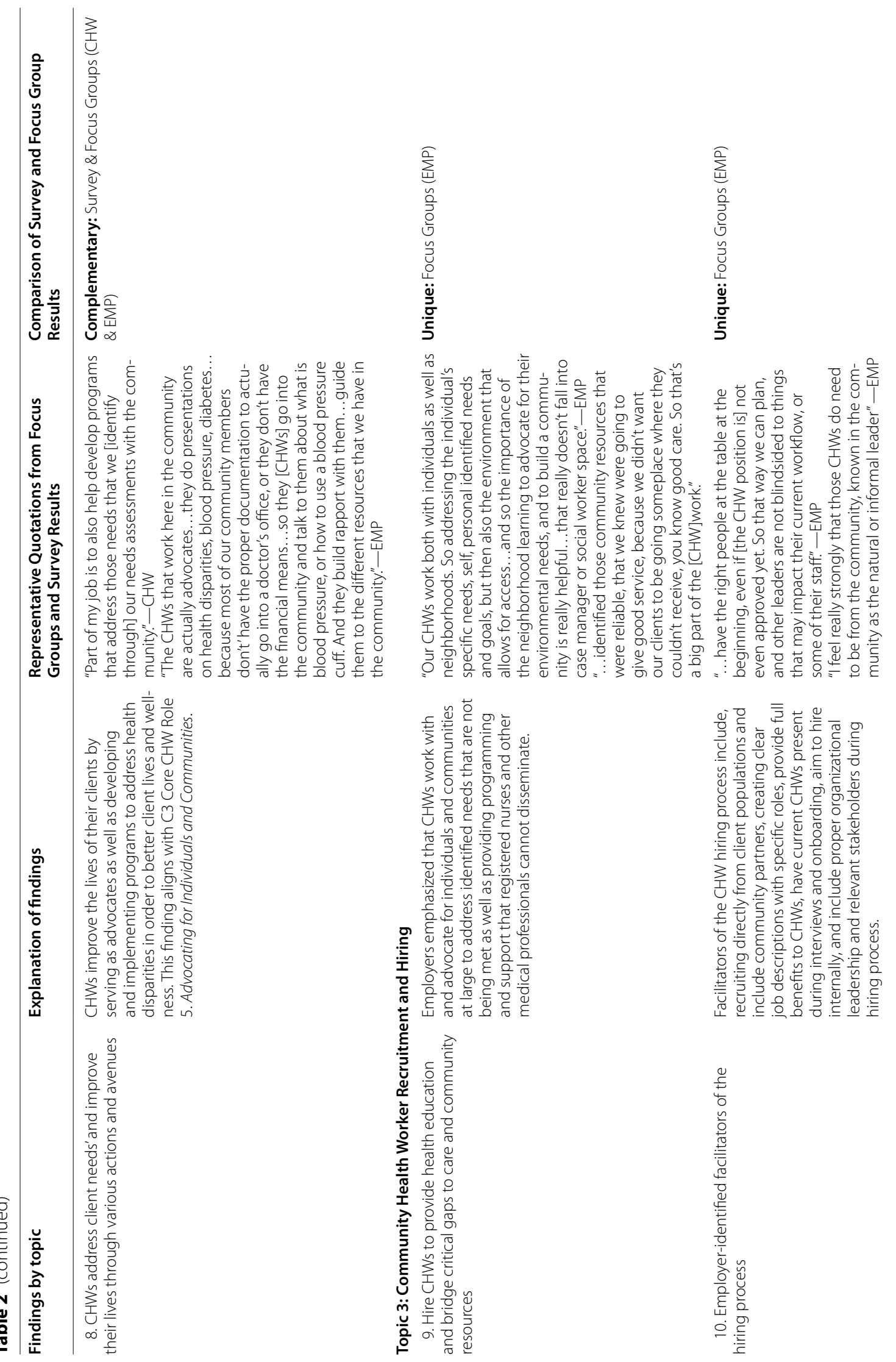


Rodriguez et al. BMC Health Services Research ～（2022) 22:117

Page 8 of 24

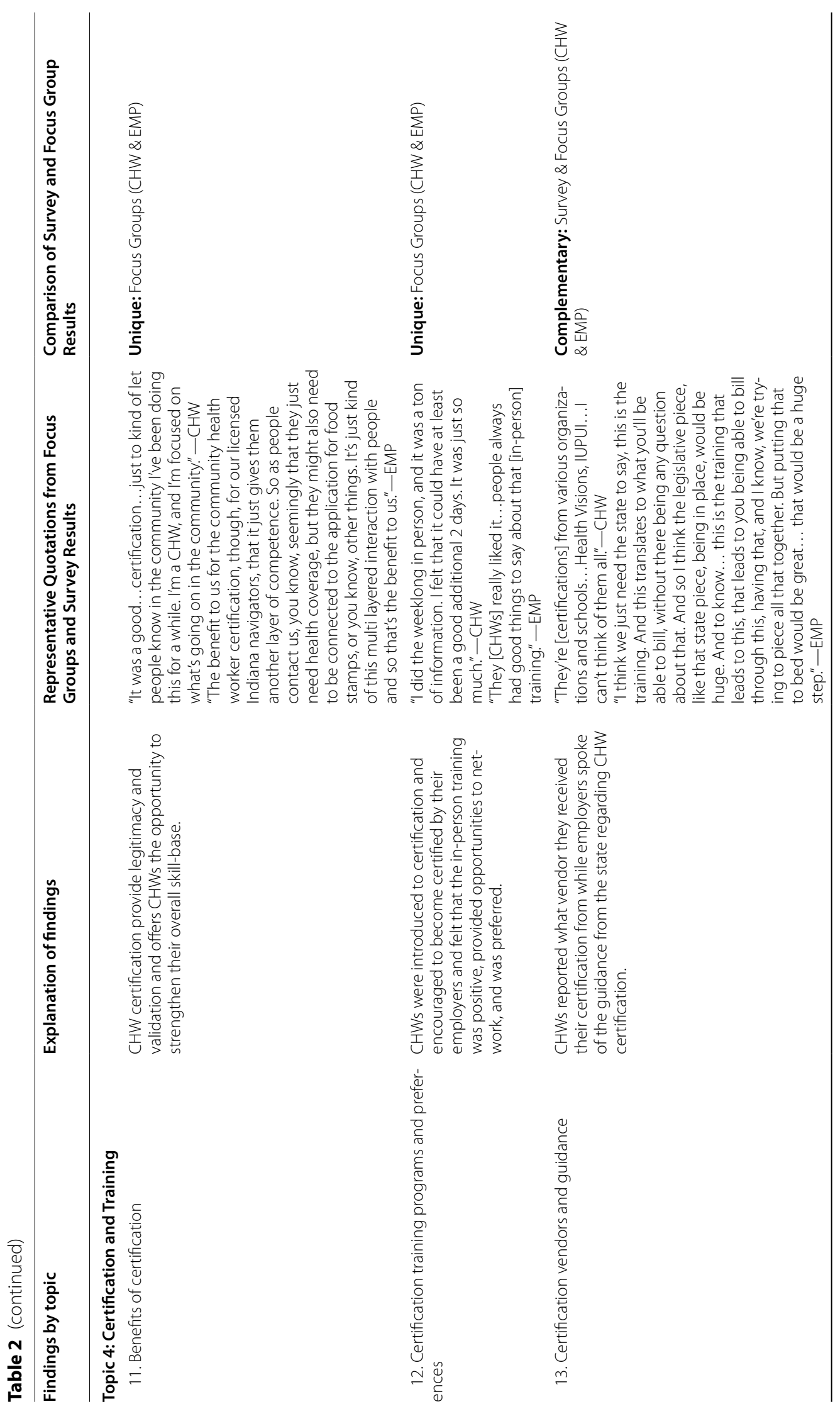




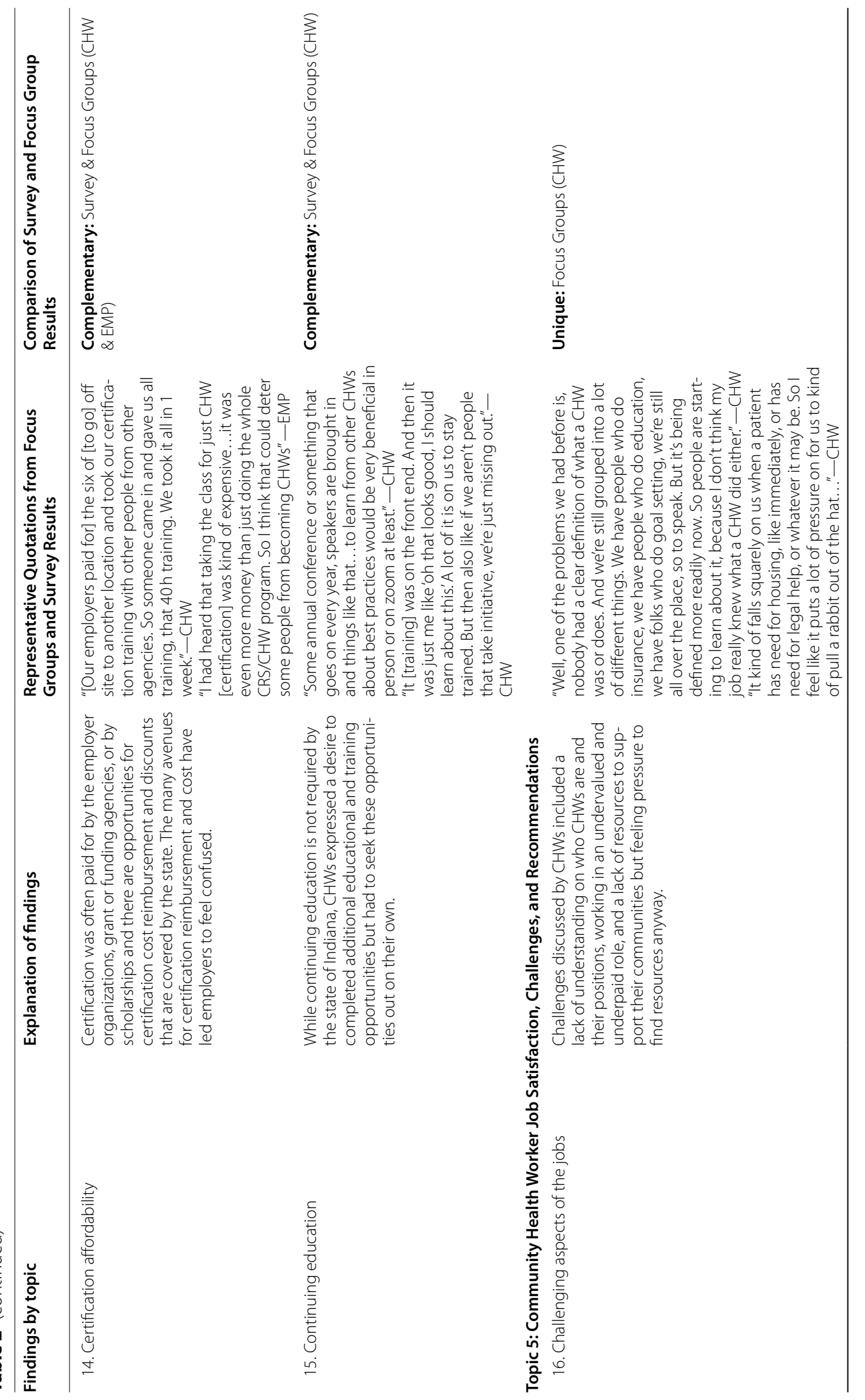




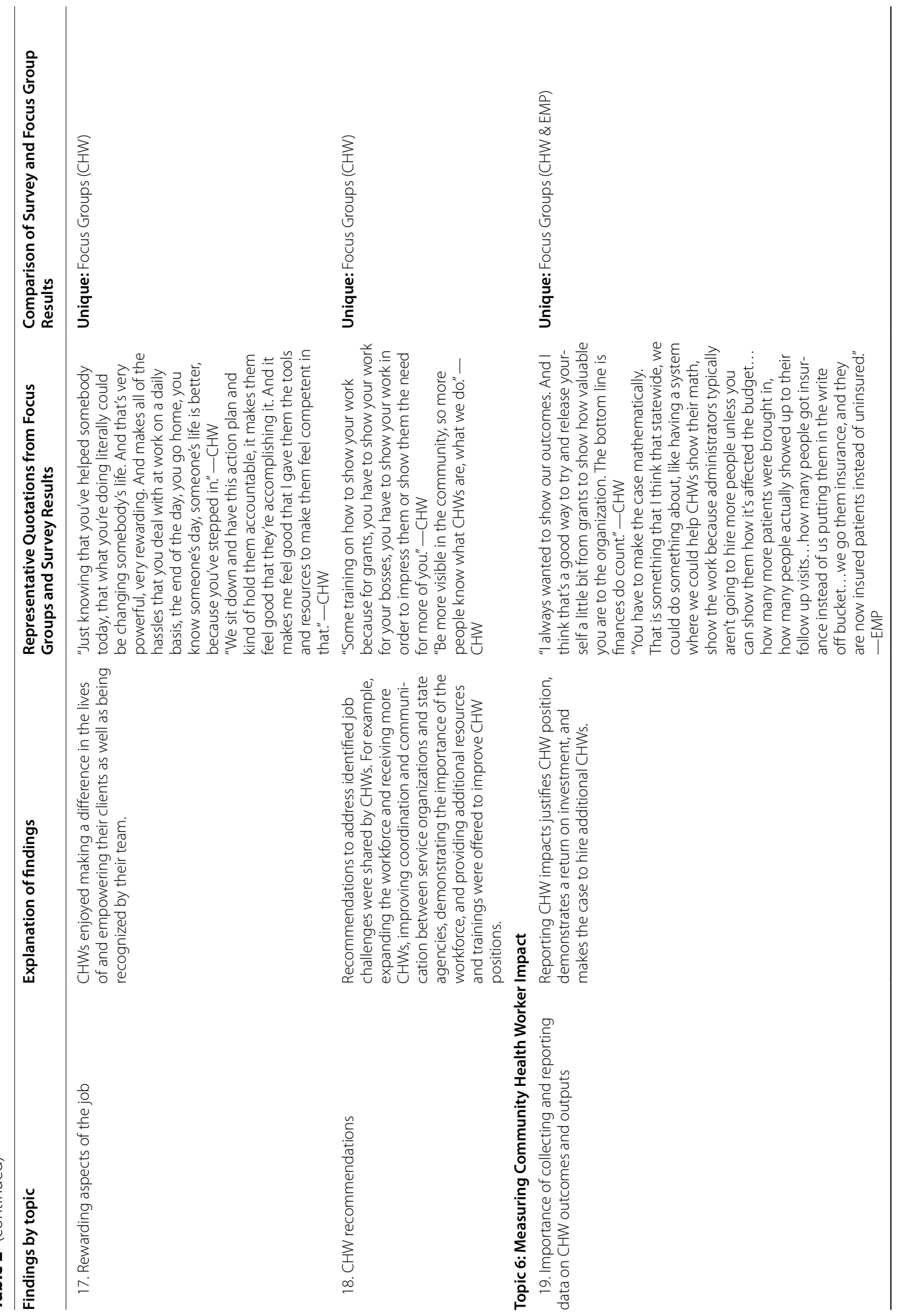




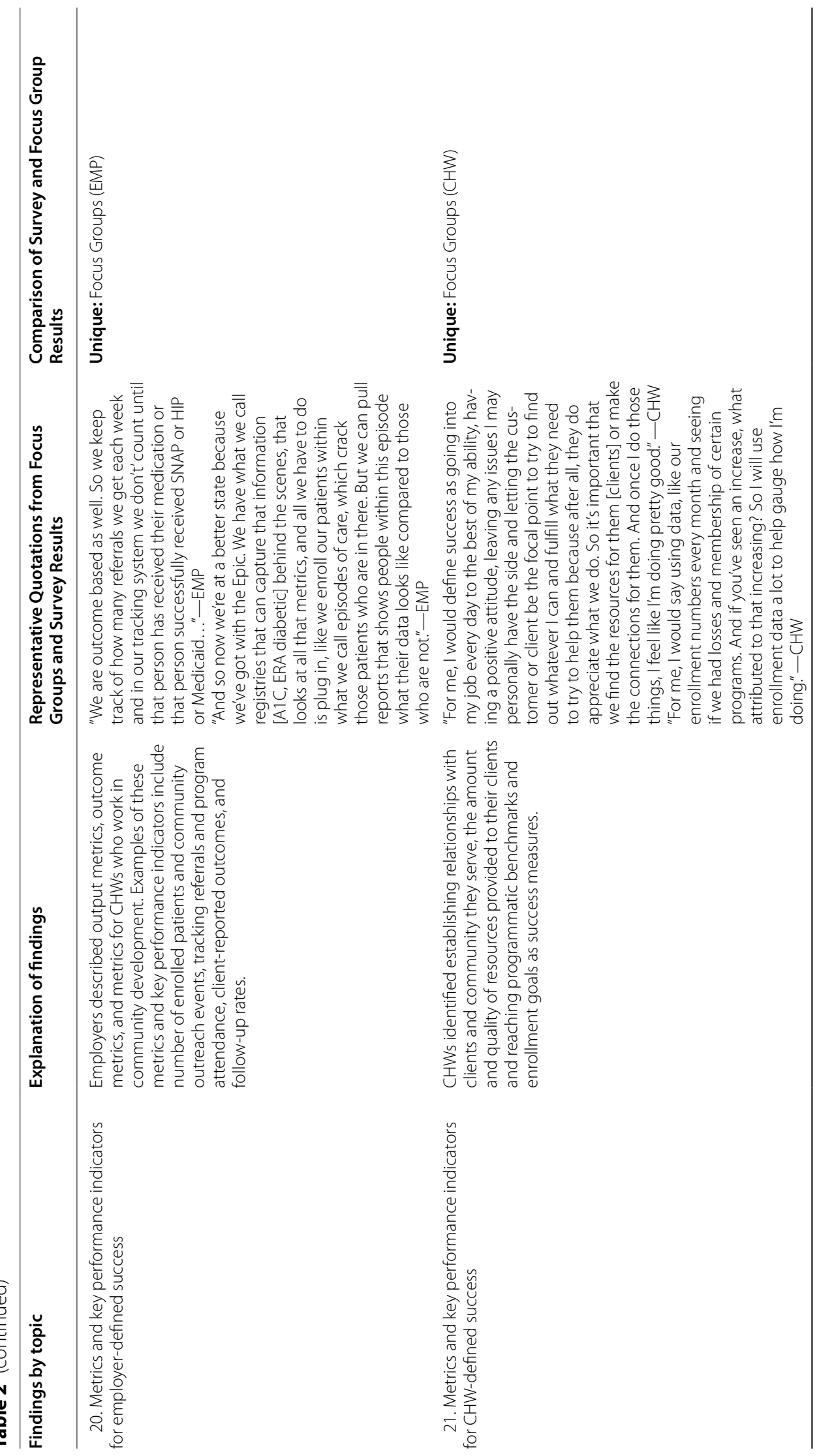




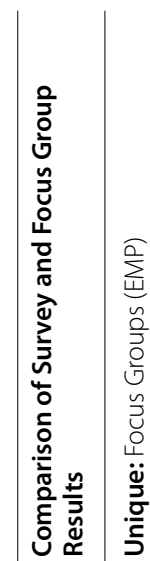

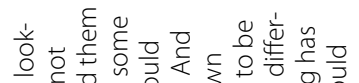

$\stackrel{n}{\breve{c}}$

है

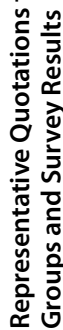

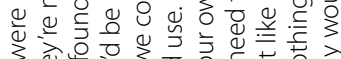

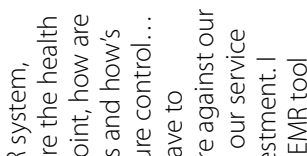

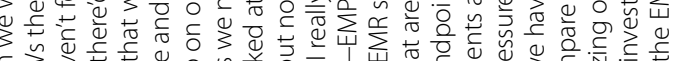

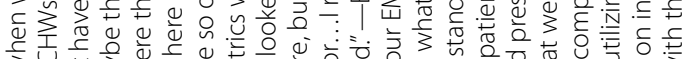

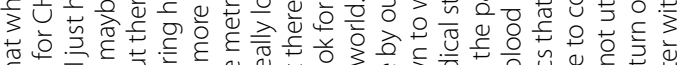

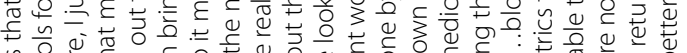

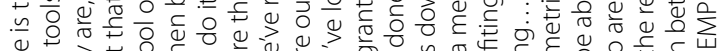

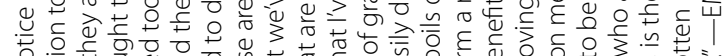

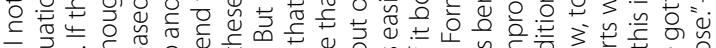
웅

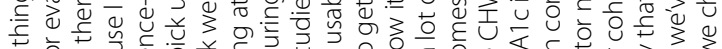

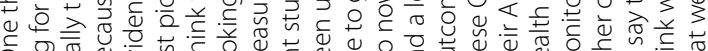

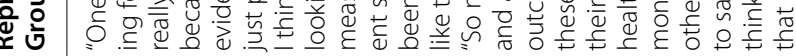

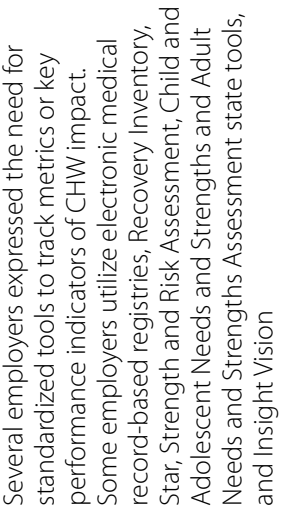

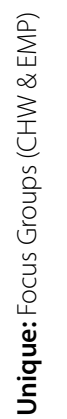
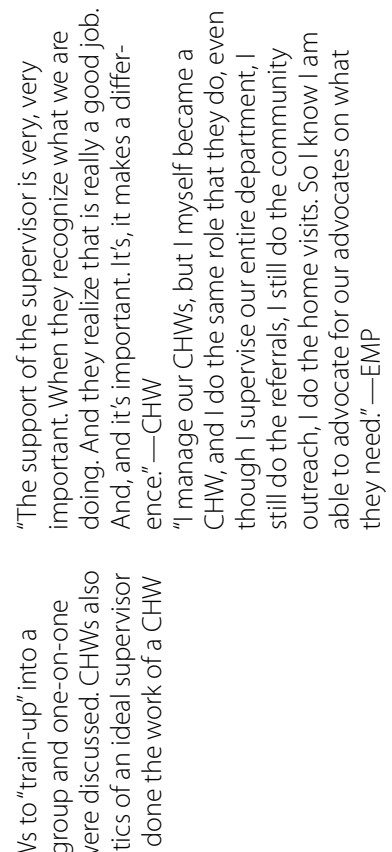

능

年

每

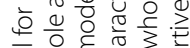

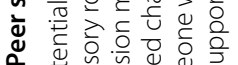

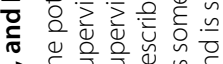

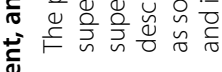

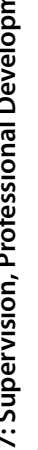

는 


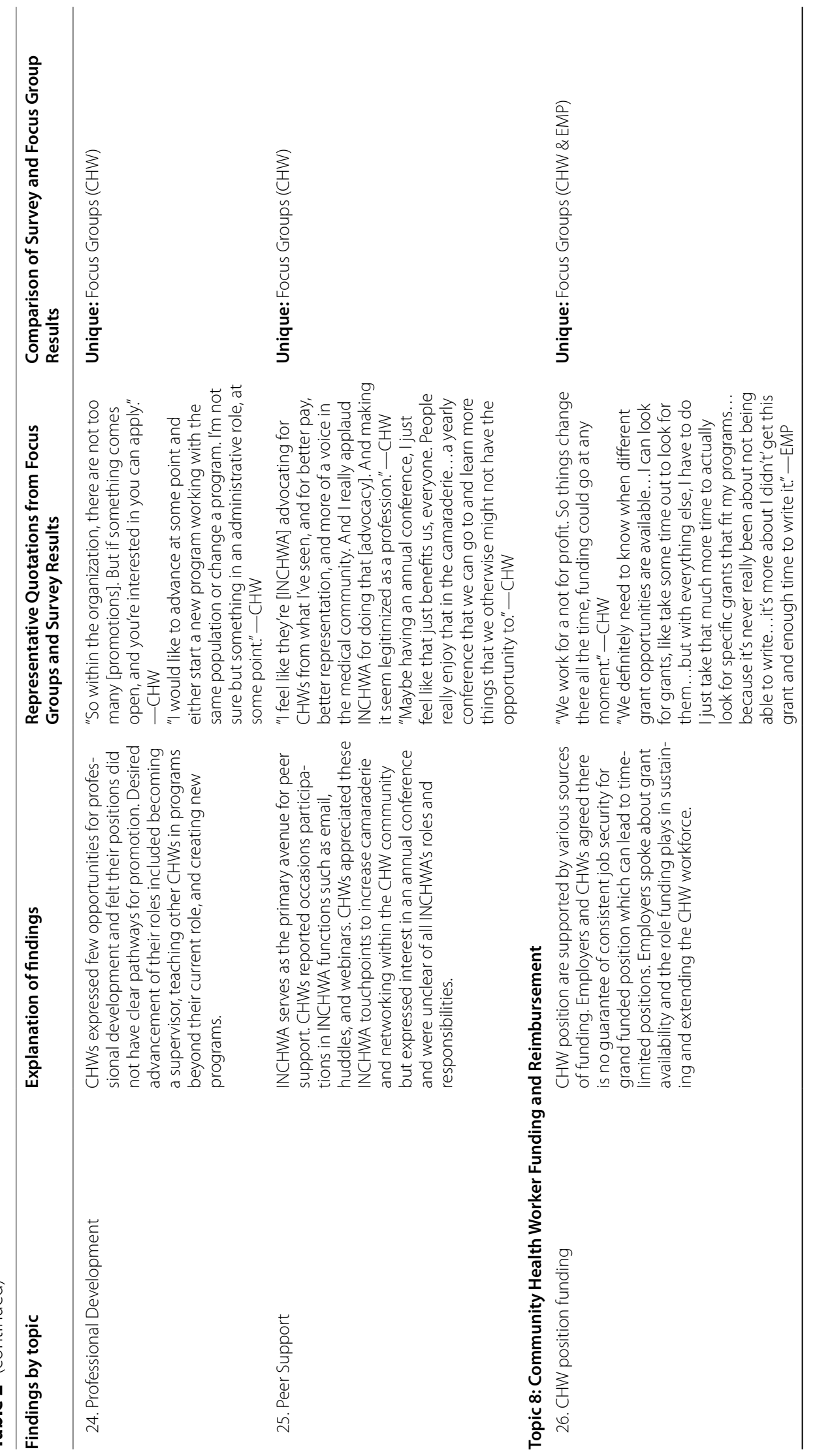




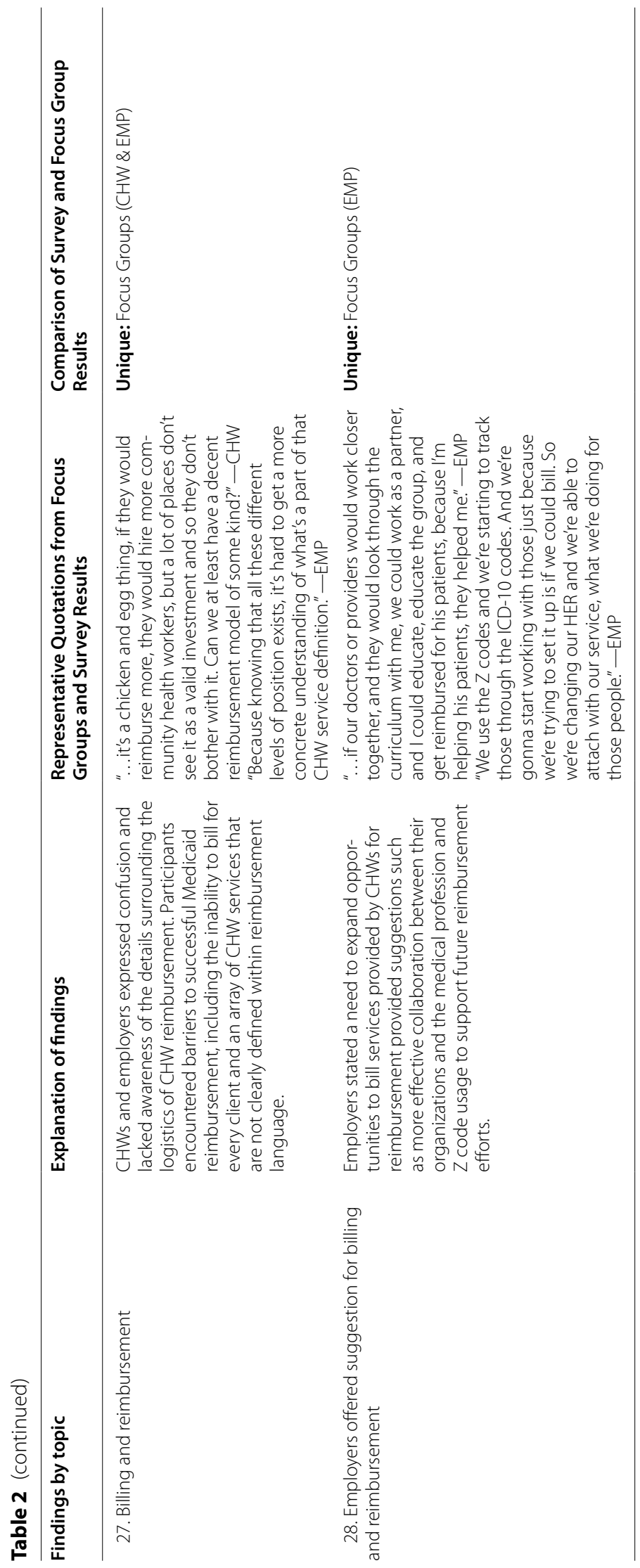


Table 3 Community Health Worker Job Titles

\begin{tabular}{ll}
\hline Job Title (N = 648) & No. (\%) \\
\hline Community health worker & $208(32)$ \\
Certified recovery specialist & $102(16)$ \\
Certified recovery specialist/Community health worker & $90(14)$ \\
Community health advisor & $55(8)$ \\
Health educator & $55(8)$ \\
Health interpreter or translator & $37(6)$ \\
Outreach worker & $28(4)$ \\
Enrollment coordinator & $16(2)$ \\
Patient navigator & $15(2)$ \\
Family advocate & $13(2)$ \\
Peer counselor & $3(1)$ \\
Other title & $24(4)$ \\
Did not respond & $2(1)$ \\
\hline
\end{tabular}

Table 4 Primary Sectors Represented

\begin{tabular}{ll}
\hline Sector $(\mathbf{N}=\mathbf{6 4 8})$ & No. (\%) \\
\hline Social and community services & $155(23.9)$ \\
County health department & $97(15)$ \\
Private health sector & $85(13.1)$ \\
Civic engagement & $80(12.3)$ \\
Managed care organization & $58(9)$ \\
Advocacy & $29(4.5)$ \\
Public safety and law enforcement & $29(4.5)$ \\
Business & $26(4)$ \\
Education & $17(2.6)$ \\
Federally qualified health center & $14(2.2)$ \\
Government & $11(1.7)$ \\
Other & $9(1.4)$ \\
Did not respond & $36(5.6)$
\end{tabular}

develop this between themselves and their clients such as having patience, the ability to create a safe space, and the need for "compassion and passion for what you are doing." Additionally, CHWs understand the importance of "meeting [clients] where they are" and of being creative and flexible. Being adaptable also helps CHWs overcome obstacles when carrying out their work as they, "come up against... a lot of barriers, and you've got to be very creative at how you address... those issues. You don't want to burn any bridges."

A key CHW role is the ability to "serve as a resource for people that I come in contact with." As such, they often become a point person for their clients or "that one consistent face and voice that [clients] could contact." They view "knowing the resources that we have in the community [as] very important" as it strengthens their capacity to connect clients to needed medical
Table 5 Demographics of Communities Served

\begin{tabular}{|c|c|}
\hline Variables $(\mathrm{N}=648)$ & No. (\%) \\
\hline \multicolumn{2}{|l|}{ Sex } \\
\hline Male & $386(60)$ \\
\hline Female & $228(35)$ \\
\hline Both & $22(3)$ \\
\hline Other & $6(1)$ \\
\hline Did not respond & $6(1)$ \\
\hline \multicolumn{2}{|l|}{ Race/Ethnicity } \\
\hline White & $285(43)^{*}$ \\
\hline Black or African American & $44(7)$ \\
\hline Asian & $12(2)$ \\
\hline Hispanic or Latino & $12(2)$ \\
\hline Native Hawaiian or Pacific Islander & $4(1)$ \\
\hline Two or More Races & $288(44)$ \\
\hline Did not respond & $3(1)$ \\
\hline \multicolumn{2}{|l|}{ Age } \\
\hline Children (younger than 12) & $23(4)$ \\
\hline Adolescents (13-18) & $151(23)$ \\
\hline Adults (18-65) & $409(62)$ \\
\hline Elderly (older than 65) & $62(10)$ \\
\hline Did not respond & $3(1)$ \\
\hline \multicolumn{2}{|l|}{ Immigration status } \\
\hline U.S. born/native & $523(81)$ \\
\hline Foreign-born/immigrant & $113(17)$ \\
\hline Refugees & $8(1)$ \\
\hline Did not respond & $4(1)$ \\
\hline \multicolumn{2}{|l|}{ Type of community primarily served } \\
\hline Rural & $117(18)$ \\
\hline Urban & $377(58)$ \\
\hline Suburban & $133(21)$ \\
\hline Did not respond & $21(3)$ \\
\hline
\end{tabular}

*Due to a classification error in the survey, the category of "American Indian or Alaska Native" is combined here with the category of "White". Based on US census data, American Indian and Alaska Native accounts for $0.4 \%$ of the population of Indiana

and social services. As trusted resources, CHWs often advocate for change, "I'm a health advocate, here at the hospital we have all kinds of projects. Our goal is to break those barriers [experiences by clients, such as] why people sit in the ER forever, you know, constantly, they can't afford their medications, utilities...just can't get to the doctors...the transportation." In addition to linking clients to resources, CHW responsibilities involve providing case management, offering health programming, and working with clients to set health and wellness goals. Survey results revealed that CHWs work within a wide breadth of health-related topics with chronic disease management being a key focus (13\%) (Table 6). 
Table 6 Primary Focus Area

\begin{tabular}{ll}
\hline Focus Area (N=648) & No. (\%) \\
\hline Chronic disease management & $81(12.5)$ \\
Behavioral/mental health & $69(10.6)$ \\
General health systems navigation & $47(7.3)$ \\
Adolescent health & $40(6.2)$ \\
Environmental and occupational health & $37(5.7)$ \\
Social service eligibility screening & $33(5.1)$ \\
Substance abuse & $29(4.5)$ \\
Men's health & $23(3.5)$ \\
Emergency response & $22(3.4)$ \\
Asthma & $22(3.4)$ \\
Communicable diseases (not HIV/AIDS) & $20(3.1)$ \\
Dental health & $19(2.9)$ \\
Elder health & $18(2.8)$ \\
HIV/AIDS & $18(2.8)$ \\
Domestic violence & $16(2.5)$ \\
Enrollment & $16(2.5)$ \\
Cancer & $15(2.3)$ \\
Prevention (nutrition/physical activity) & $15(2.3)$ \\
Community violence & $14(2.2)$ \\
Maternal and child health & $14(2.2)$ \\
Injury prevention & $14(2.2)$ \\
Smoking and tobacco use & $13(2)$ \\
Women's health & $12(1.9)$ \\
Lead poisoning & $8(1.2)$ \\
End of life & $8(1.2)$ \\
LGBTQ+ issues & $6(0.9)$ \\
Tuberculosis & $2(0.3)$ \\
Veterans'services & $2(0.3)$ \\
Other & $14(2.2)$ \\
Did not respond & $3(0.5)$ \\
\hline
\end{tabular}

\section{Topic 3: recruitment and hiring}

Employers shared ways that hired CHWs enhanced their organizational work as "there was so much that our registered nurses and dietitians and registered respiratory therapists couldn't complete...so CHWs were hired to help us close those gaps." When hiring future $\mathrm{CHWs}$, employers looked for professionalism, flexibility, and organizational and communication skills. Employers also expressed a preference for bilingual candidates with an existing connection to the focus community, "We really try to hire from within that community. So we're getting people who know the community, they know the resources, they know people coming into the clinic." During the hiring process, employers reported turning to organizational leadership, community partners, and currently employed CHWs. Successful CHW hiring strategies included drafting clear job descriptions, recruiting directly from client populations, hiring $\mathrm{CHW}$ cohorts for group training and onboarding, and providing employee benefits.

\section{Topic 4: certification and training}

After analysis, among the CHWs surveyed, over $80 \%$ $(n=526)$ reported being certified, more than $50 \%$ $(n=368)$ found CHW employment as a result of certification, $12 \%(n=75)$ had a CHW position before becoming certified, $5 \%(n=35)$ did not find CHW employment, and $6 \%(n=40)$ did not seek CHW employment. Participants shared that certification provided CHW work with legitimacy and validation, "being certified as a CHW, just kind of gives us that little bit of ..., I guess, upper level, you know what I mean?" Certification also seemed to offer CHWs an opportunity to strengthen overall skills, knowledge, and training, "...it's just good to have that [training] knowledge and background and experience to add to what we do every day."

Surveyed CHWs shared an unawareness of certification when they entered the workforce but were asked to complete certification by their employer. Most $(n=492$; 76\%) $\mathrm{CHWs}$ reported employers paying for the $\mathrm{CHW}$ certification; employers use state-funded training and workforce development reimbursement programs to do so. However, employers shared inconsistencies in terms of sponsors, certification type (e.g., combined $\mathrm{CHW} /$ Certified Recovery Specialist [CRS], stand-alone CHW certification), and cost, "... it [certification] was kind of expensive... it was even more money than just doing the whole CRS/CHW program. So I think that could deter some people from becoming CHWs."

Both CHWs and employers expressed being confused by the different certification programs as some are recognized by the certifying state agency while others are not. They also shared frustration over the lack of clear guidance related to which certification$\mathrm{CHW}$ versus $\mathrm{CHW} / \mathrm{CRS}$ - is approved for reimbursement. Participants expressed a strong preference for in-person trainings over online versions as it provided an opportunity to connect and network with other CHWs and "...to help with engaging and just the motivational interviewing skills. I mean, there's some things that you can't learn by using the computer and doing virtual." While most agreed, some described the required week-long training as quite intensive and suggested that the in-person training be extended or spread across a longer time-period.

\section{Topic 5: job satisfaction and challenges}

Making a difference in people's lives was described as a rewarding aspect of CHW work when "you can 
see how you affected them or how, you know, you're even able to make them believe in themselves, which is huge." Being recognized by the medical team was also seen as rewarding: "I feel like the medical team really recognize after, you know, they definitely are thankful and appreciative of the help that we provide." Despite the rewards, CHWs continue to face challenges due to a general lack of awareness of who the CHW workforce is and what they do, which "...a lot of the time with CHWs, I think that what we do is not valued. So we don't really get paid that amount that we should get paid." CHWs also described barriers such as a lack of resources to help the vulnerable people they serve, which can exact heavy physical and emotional costs. CHWs discussed ways to address these challenges including creating "more acceptance of what we do and being more respected as a profession because this is a profession."

\section{Topic 6: measuring impact}

Both CHWs and employers identified a need to document the impact of CHW work because "...you help that one person today, you did just a little something for somebody here and there. Over time, that's going to add up to big success." CHWs expressed wanting to be involved in defining and measuring this impact and suggested that metrics to include (e.g.; established community relationships, resource provision to clients, programmatic benchmarks, enrollment goals). Employers agreed a need exists to document $\mathrm{CHW}$ impact that supports return-on-investment (ROI) to justify current and future CHW hiring lines. Employers shared various client- and program-level metrics used to track CHW efforts (e.g.; community outreach events conducted, completed screening tools, number of goals set/achieved with clients, changes in knowledge gains, follow-up rates). Employers also discussed community-specific indicators, such as emergency room utilization rates, changes in public safety calls, number of jobs created, and greenspaces developed/improved. Additionally, they explained that metrics from existing registries and assessments are used, such as electronic medical record (EMR)based registries, Recovery Inventory, Star, Strength and Risk Assessment, Child and Adolescent Needs and Strengths and Adult Needs and Strengths Assessment (CANS/ANSA) state tools, and Insight Vision. Despite these existing approaches, employers agreed that efforts are needed to standardize current tools, reporting systems need to align with existing EMR systems, measures are needed across the social determinants of health, and systems created to build evaluation capacity.
Topic 7: supervision, professional development, and peer support

Being relatable, supportive, and familiar with $\mathrm{CHW}$ work were identified as characteristics of an ideal supervisor, "I need a supervisor who does this job... And I want someone who has done the work to be able to 'train up' others and also be that lead..." Related to professional development, CHWs expressed wanting access to supervisor encouraged and funded trainings and certifications that go beyond initial CHW certification, but shared that professional development opportunities are not readily available and costs fall upon the CHWs themselves. CHWs shared interest in on-the-job training in particular areas (e.g., home visits, and going into homes), and access to annual conference or annual/quarterly trainings in order to stay current in the field and learn from peers. CHWs also expressed concern over lack of career advancement pathways, "so within the organization, there are not too many [promotions]." Despite the absence of professional advancement, $\mathrm{CHWs}$ expressed a desire to expand their current position to include supervision and training of other CHWs, "I would like to teach the classes as well as even after going through the course, inquired about how to become an instructor."

CHWs expressed a strong interest in connecting with other CHWs in person at their workplace and through annual conferences. They described INCHWA as playing a key role in providing $\mathrm{CHW}$ peer support by engaging CHWs via email, huddles, and webinars, "I do find the INCHWA emails and newsletters to be helpful...that's really the only connection that I have to anyone else." They also felt that INCHWA's efforts to advocate for the profession were needed and appreciated.

\section{Topic 8: funding and reimbursement}

CHW positions are primarily funded through county, state, and federal grants or soft-monies and, to a lesser degree, by institutional or hard-money leading to concerns related to job security, "We work for a not for profit, so things change all the time. Funding could go at any moment..." Both employers and CHWs shared how soft-money funded programs place employees at risk for unexpected terminations: "...their [CHW] grant was from the Office of Minority Health, they really hated it because it got pulled in year three and they had made so much progress...I'm staying away from grants because you can't trust them. The work they did was so valuable...so it was really sad they couldn't finish."

Participants expressed confusion and lacked understanding related to $\mathrm{CHW}$ billing for Medicaid reimbursement. They shared concern regarding the sustainability of a business model that relies on the current CHW reimbursement structure given that it does not allow for 
billing of clients with a diverse payer mix, does not provide payment for $\mathrm{CHW}$ services provided on the same day as other provider services, and fails to cover a broad spectrum of CHW services, "But I think that insurance companies like Medicaid and SSI would benefit in the long run, if they covered more of the services CHWs do because they're all services that keep their patients, their customers in compliance." Both CHWs and employers agreed that applying for $\mathrm{CHW}$ reimbursement through Medicaid is cumbersome, confusing, and complex, "...it would be nice to see more guidance on what's considered appropriate within those ranges...it's hard to get a concrete understanding of what's a part of that CHW service definition." Employers discussed the potential of $\mathrm{Z}$ code usage, and that more effective collaboration among doctors, providers, and CHWs would be needed to address these challenges, "...if our doctors or providers would work closer together, and they would look through the curriculum with me, we could work as a partner, and I could educate, educate the group and get reimbursed for his patients."

\section{Discussion}

With growing evidence of the clinical and social impact of CHWs in communities that are underserved, there is an increased national demand for CHWs. Despite this, some US states continue to face challenges related to funding, training, expanding, and sustaining their CHW workforce [24]. Engaging key stakeholders from multiple perspectives and utilizing a multi-methods assessment approach provided invaluable insight into the strengths, needs, and landscape of the $\mathrm{CHW}$ workforce in Indiana. These collaborative efforts positioned us to prioritize actionable recommendations. Research findings demonstrated the strengths and diversity of Indiana CHWs and informed the authors' four key recommendations for expanding and sustaining Indiana's CHW workforce. These recommendations are transferable to other states with similar contexts and can be implemented sequentially or concurrently with no prescribed order (Fig. 1).

\section{Recommendation 1: standardize, build, and maintain a database on the roles and impact of $\mathrm{CHWs}$ in Indiana}

Scaling and sustaining CHW positions is best facilitated through accessible information documenting the roles, responsibilities, and impact of CHWs. Clearly defining CHW roles to healthcare providers allows for better $\mathrm{CHW}$ integration into healthcare organizations, improving overall health outcomes $[6,25]$. Maintaining an Indiana CHW registry will allow compilation of up-to-date statistics on workforce density, geography, certification

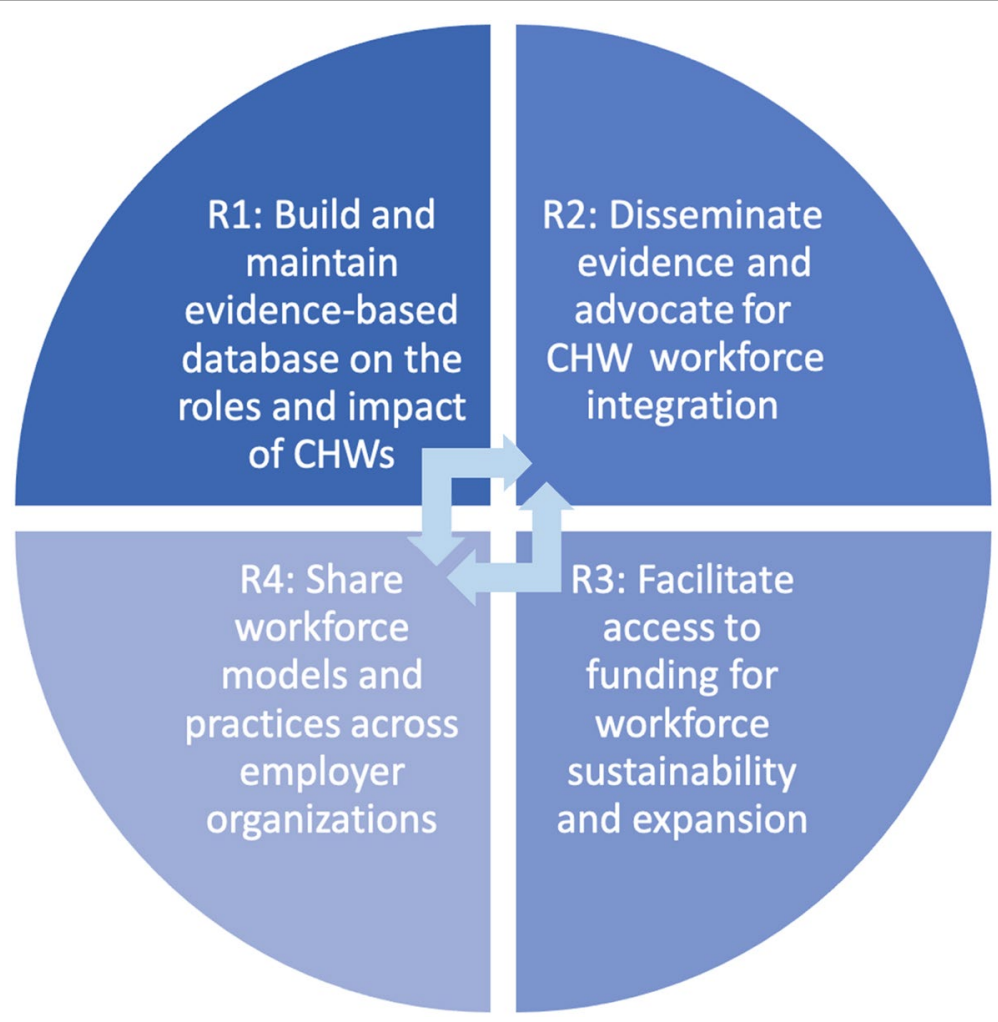

Fig. 1 Key recommendations for expanding and sustaining Indiana's CHW workforce 
levels, areas of work, employment, and income. With standardized data collection across employer organizations, it is possible to measure the full impact of $\mathrm{CHW}$ services and demonstrate ROI, as well as establish standardized and sector-specific metrics for $\mathrm{CHW}$ outputs and outcomes. Ingram et al. [4] described the use of electronic health records to examine the effect of $\mathrm{CHW}$ services on chronic disease outcomes. The Arizona Community Health Worker Association and the $\mathrm{CHW}$ Workforce Coalition spent 2 years gathering data from and about CHWs and community health representatives serving American Indian Tribes and communities via small group sessions and annual meetings. These data later informed a formalized assessment of $\mathrm{CHW}$ mastery of core competencies as well as a process to approve training programs throughout the state [26]. Our recommendation to build and maintain an up-todate evidence based CHW registry and database could serve as a more efficient approach to collecting data, and meaningfully build upon the mounting evidence of positive health outcomes associated with the integration of CHWs into patient care across the country [3-5, 27-32]. These standardized data can be used to inform and catalyze advocacy and policy efforts towards creating and/or refining standardized state training programs, pathways for certification, employment, and sustainable funding for the $\mathrm{CHW}$ workforce.

\section{Recommendation 2: disseminate evidence and educate employers and communities about the $\mathrm{CHW}$ profession} to advocate for $\mathrm{CHW}$ workforce integration and expansion

Dissemination of evidence can be more easily achieved upon establishment of the evidence-based database (Recommendation 1), which could inform the development of dissemination products, such as informational materials and strategies, and can equip all applicable stakeholders with increased clarity and understanding of the CHW profession, associated roles, and impact on health outcomes. The National Association of Community Health Workers (NACHW) document resource center is one example of data dissemination, which is accessible on the NACHW website for free and includes study reports, policy briefs, fact sheets, and more from researchers and CHW organizations across the country [33]. In accordance with Sabo et al. [24], we recommend that evidence be distributed in lay language and accessible through a variety of outlets (e.g., social media, newsletters, workshops, interactive presentations at staff meetings), in the preferred language of the focus community. Communities who understand the role of CHWs will be more trusting of the profession and are better poised to leverage $\mathrm{CHW}$ services. Employers who know the demands of the job are also in a better position to take the steps to adequately support the workforce [34]. Yearly reviews and pre- and post-program implementation analyses are vital in promoting workforce development. Frequent data analysis and dissemination of organizational-level CHW impact metrics will support evidence-based advocacy for the workforce. Impact metrics can include the number of enrolled patients, client evaluation forms, follow-up rates, and community-specific indicators such as a reduction in emergency room use [2]. The C3 Project, which aims to increase visibility and a greater understanding of CHWs, created a publicly available CHW assessment toolkit. The toolkit allows for field-oriented, evidencebased recommendations and resources that aid in the holistic assessment of CHW impact [23]. Similarly, our recommendation supports creating and disseminating informational products that are readily accessible and can demonstrate the positive impact that CHWs have on their communities, thus, leading to opportunities for increased funding, expanded policy initiatives and resources for employing and retaining CHWs.

\section{Recommendation 3: facilitate understanding and promote access to and utilization of existing funding mechanisms for $\mathrm{CHW}$ workforce sustainability and expansion}

An underutilized and misunderstood billing framework for reimbursement of $\mathrm{CHW}$ services leads to a lack of sustainable funding for permanent $\mathrm{CHW}$ positions. Inconsistent funding jeopardizes $\mathrm{CHW}$ recruitment and retention, as well as program implementation. Ensuring sufficient funds through extensive cost analyses that consider expenses associated with continued training, sufficient supervision, and integration of CHWs into healthcare systems is vital [34]. There are various CHW funding strategies to be explored, including reimbursement for non-clinic based CHWs, and leveraging existing state workforce development programs. Our study findings suggest that the existing Medicaid reimbursement policies in Indiana require improved clarity and employer education to increase appropriate utilization [2]. Ibe et al. [35] concluded that more research needs to be conducted to gain a better understanding of $\mathrm{CHW}$ certification and its' impact on patient health outcomes. Similarly, further research on the role of $\mathrm{CHW}$ certification in supporting the financial sustainability and workforce development of CHWs in the US is warranted.

A well-maintained evidenced-based $\mathrm{CHW}$ database (Recommendation 1) could facilitate advocacy efforts regarding reimbursement rates to be commensurate with the impact of CHWs and better alignment with similar position policies (i.e., Certified Recovery Specialists). Furthermore, the current public health climate due to the Coronavirus Disease 2019 (COVID-19) pandemic has generated additional federal funding mechanisms 
for $\mathrm{CHW}$ career paths. A more recent avenue of federal funding is the increased public health workforce funding through the Centers for Disease Control and Prevention (CDC). As of March 2021, the CDC planned to provide $\$ 300$ million towards CHW services to support COVID19 control and prevention and an additional \$32 million towards training, technical assistance, and evaluation of CHWs [36]. President Biden's plan included increasing the CHW workforce by 150,000 nationally and pledged to provide direct grant funding, as well as add $\mathrm{CHW}$ services as an optional benefit for states through Medicaid [37]. States can better maximize the sustainability of the workforce as funding opportunities arise to revise existing regulations around $\mathrm{CHW}$ reimbursement.

\section{Recommendation 4: share CHW workforce models and best practices across employer organizations to optimize strategies}

Fragmented CHW employment pathways and lack of career development opportunities can lead to missed opportunities, stagnant wages, job dissatisfaction, and high turnover rates. These can be mitigated by the creation of standardized, sector-specific guidance for optimal recruitment, integration, training, and ongoing education, certification, supervision, career development, and funding of $\mathrm{CHWs}$ for employers in Indiana. The National Committee for Quality Assurance (NCQA), in partnership with the Penn Center for Community Health Workers, is a multistakeholder effort to create such standards nationally. The goal of the NCQA standards is less about dictating CHW training methods or scope of practice and more about providing evidence-governed guidelines for the systems in which CHWs work [38]. Involving CHWs at all levels of decision-making related to the workforce will streamline communication across CHW employer organizations, state agency partners, and other stakeholders to align statewide efforts. Yearly reviews of national CHW models and standards should be conducted to remain aligned with best practices outside of Indiana and coordinate with efforts already underway (e.g., APHA-CHW section, NACHW). Demonstration projects can allow for the development of context-specific guidance to help integrate $\mathrm{CHWs}$ and scale up workforce models into organizational strategic plans, teams, and workflows across the state.

\section{Limitations}

There were several limitations to this study. While our steering committee guided our work, participants of the focus groups did not capture all potential stakeholders (e.g., unemployed CHWs, policy makers, and national organizations who work with CHWs). A disproportionate percentage of CHWs selected "American Indian or Alaska Native" as their race/ethnicity which is inconsistent with the known demographics of Indiana. Future surveys should be created to more clearly delineate the race/ethnicity of all respondents in order to avoid this classification error. Methods taken to eliminate potentially duplicative and fraudulent survey responses as described above may have inadvertently eliminated legitimate responses. Future online surveys should utilize software features, such as prevention of "ballot stuffing". Lastly, the findings presented here are specific to Indiana and may not be generalizable to all states; thus, each state should identify unique nuances of the $\mathrm{CHW}$ workforce in their geographic region.

\section{Conclusion}

CHWs come from diverse cultural and linguistic backgrounds, with an existing connection and relatability to the focus community-valued attributes and characteristics by employers. Through their knowledge base, skills, and social networks, CHWs excel at serving as an essential conduit for locating and connecting clients with both social and medical resources which leads to reduced health disparities and improved individual and community health outcomes. A high need for CHWs exists across community and clinical settings; however, employers often lack the ability to obtain and sustain proper funding to meet this demand. Despite a growing $\mathrm{CHW}$ workforce, a consistent foundation and understanding of $\mathrm{CHW}$ positions and capabilities is lacking. Creating consistency and a greater understanding regarding $\mathrm{CHW}$ models, measures, evidence-based practices, funding and reimbursement policies, and training and certification is crucial to optimize strategies and build workforce capacity locally and nationally.

\section{Appendix \\ Appendix A: Employer and CHW Focus Group Guides INTRODUCTION}

1. How many CHWs does your organization currently employ?

a. How many would you ideally like to employ/have capacity for?

b. Do you have imminent needs/plans in place to hire more CHWs?

2. How and from where do you/would you recruit your org's CHWs? 
a. Are CHWs hired to work within their own community?

3. What do the CHWs employed by your organization do?

a. Are there specific tasks and why were CHWs specifically hired to do that? (As opposed to social workers, etc....)

\section{IMPACT/OUTCOMES}

1. What strengths do the CHWs bring to your org?

2. What data are you collecting to measure their impact/success?

3. On a scale of $1-5$, how important is it for your organization to prioritize the expansion of CHWs?

\section{BARRIERS TO CHW EMPLOYMENT/SUSTAINABILITY}

4. How are you currently financially supporting CHWs within your organization?

a. Has that changed?

b. Is it only based on grants? Is it for specific projects? What happens when projects end?

c. Are any purely volunteers?

5. In what ways have you had to justify $\mathrm{CHW}$ positions in your budget?

a. Besides above, is there additional specific data you need to collect for your grants?

6. Do you currently utilize CHW education codes for Medicaid reimbursement?

a. If no:

i. Why not? What are the challenges? Have you heard of this?

ii. If you could propose a new reimbursement model, what would it look like? i. Please describe the process of billing and reimbursement.

ii. What's working?

iii. What's not?

iv. Does the reimbursement sustain the entire $\mathrm{CHW}$ position or are other sources of funding needed?

v. If you could propose a new reimbursement model, what would it look like?

7. Think about when you first created a CHW position. What are the barriers you faced for implementing this position?

a. Thinking about your current CHW model/positions, what are the barriers you face for sustainability and/ or expansion?

i. How do you identify the next population/community to expand to?

8. What resources do you need to implement or sustain CHW positions?

a. What kinds of support/trainings do you as employers need? (What kind of support could you use in order to maintain a budget line for your CHWs or bring in new funding for new projects/expansion)

b. What kinds of support/trainings do your CHWs need?

9. Who is currently training your CHWs?

a. Is certification required for employment? Whose responsibility is it to pay for certification?

b. Are they trained for specific projects?

c. Do you offer/support CE or additional training opportunities?

\section{SUPERVISION}

10. What do supervision models look like for CHWs?

11. What do career development models look like for CHWs?

a. Are there clear pathways for promotion?

b. If yes:

(a)




\section{What else would you like us to know about CHWs within your organization? \\ CHW Focus Group Guide INTRODUCTION}

1. What led you to become a CHW?

2. What are the main goals of your job?

3. If you could change anything about your $\mathrm{CHW}$ responsibilities, what would it be?

- Is there more you would like to do to support the clients you work with?

4. What makes you a good CHW? What strengths/ skills do you bring to your position?

\section{JOB SATISFACTION/WHAT MAKES GOOD JOB}

5. What do you find most rewarding about your job?

- Do you feel recognized and respected in your position?

- What is the potential for growth in your position?

- Would you refer friends and family members to becoming a CHW and working in this field? Why or why not?

6. Do you feel you are compensated fairly in your current position?

7. What is the \#1 challenge of your job?

8. What resources do you need to do your job more effectively/efficiently?

9. How does your employer define success of your work/position?

- If you wanted to convince your employer to hire more CHWs, what would they have to see?

COMMUNITIES THEY SERVE/ PROBLEMS

THEY'RE ADDRESSING

10. Tell us about your community that you work in. What are the biggest issues that are faced?

11. How do you define success of your work/position within the community you're serving?

\section{EMPLOYER SUPERVISION/SUPPORT}

12. Do you feel that you have job security in your current position?

- Do you feel your position is time-limited?

- What do you know about how your position is funded?

PERSPECTIVES ON CERTIFICATION AND
TRAINING

13. Think about the trainings you've received as a CHW. What additional trainings do you feel you need?

- What is your interest in ongoing training, renewal, continuing education?

14. What opportunities do you have for ongoing training?

- Do they come from your employer?

- From outside sources?

15. What are your thoughts on CHW certification?

- What was the process like?

- What would you change about the process?

- Any challenges to obtaining certification?

- Does it lead to higher wages or more/better employment opportunities? Is it worth it?

\section{PEER SUPPORT}

16. How do you connect with other CHWs within or outside of your organization?

- How do you engage with INCHWA? How does it meet your needs as a prof. Organization? What more would you like to see from INCHWA?

- In what other ways would you like to connect with $\mathrm{CHW}$ peers?

\section{PROFESSIONAL DEVELOPMENT}

17. What, if anything, would you like to do as the next stage of your career?

- What, if any, aspirations do you have beyond CHW work?

Is there anything we should have asked but didn't?

Can we contact you in the future if we have followup questions?

\section{Abbreviations}

CHW: Community Health Worker; CHWDI: Community Health Worker Development Institute; NASPH: National Academy for State Health Policy; IRB: Institutional Review Board; INCHWA: Indiana Community Health Worker Association; ROI: Return-on-Investment; EMR: Electronic Medical Record; CANS:

Child and Adolescent Needs and Strengths; ANSA: Adult Needs and Strengths Assessment; NACHW: National Association of Community Health Workers; C3: CHW Core Consensus Project; CDC: Center for Disease Control and Prevention; NCQA: National Committee for Quality Assurance.

\section{Acknowledgements}

We would like to extend our appreciation to our collaborating partners, the Indiana Community Health Worker Association (INCHWA) and the Community Health Workforce Development Institute's Steering Committee members.

\section{Authors' contributions}

NMR: Funding acquisition, conceptualization, investigation, methodology, project administration, writing — review \& editing. YR: Conceptualization, investigation, methodology, project administration, writing — review \& editing. 
AHM: Conceptualization, investigation, methodology, project administration, writing — review \& editing. CK: Data curation, formal analysis, writing —origina draft, writing — review \& editing. OAAO: Validation, visualization, writing —original draft, writing — review \& editing. LFK: Writing — original draft, writing — review \& editing. JDG: Funding acquisition, conceptualization, investigation, methodology, project administration, writing—review \& editing. The authors read and approved the final manuscript.

\section{Funding}

This project was supported by the Purdue Center for Health Equity and Innovation (CHEql) and the Indiana Clinical and Translational Sciences Institute, funded in part by grant \# UL1TR002529 from the National Institutes of Health, National Center for Advancing Translational Sciences.

\section{Availability of data and materials}

Complete data set is available for review upon request.

Please contact the first author Dr. Natalia Rodriguez to request data from this study.Email:natalia@purdue.edu

\section{Declarations}

\section{Ethics approval and consent to participate}

All methods were carried out in accordance with relevant guidelines and regulations. The Purdue University Institutional Review Board determined this research was exempt. Informed consent was obtained verbally from all participants prior to focus group participation. Additionally, there was language prior the beginning the survey that stated participation was voluntary and would not affect their relationship with the Indian Community Health Worker association.

\section{Consent for publication}

Not applicable.

\section{Competing interests}

Not applicable.

\section{Author details}

'College of Health and Human Sciences, Department of Public Health, Purdue University, 812 W. State Street, West Lafayette, IN 47907, USA. ${ }^{2}$ College of Pharmacy, Department of Pharmacy Practice, Purdue University Center for Health Equity and Innovation, 640 Eskenazi Ave, Fifth Third Bank FOB, 3rd Floor, Indianapolis, IN 46202, USA.

Received: 12 July 2021 Accepted: 22 December 2021

Published online: 27 January 2022

\section{References}

1. American Public Health Association. Community Health Workers. https:// www.apha.org/APHA-Communities/Member-Sections/CommunityHealth-Workers. Accessed March 2021.

2. Community Health Worker Development Institute. Indiana Community Health Worker Needs Assessment Report. 2020. https://cheqi.pharmacy. purdue.edu/sites/cheqi.pharmacy.purdue.edu/files/pdf/Purdue-2020CHWDI-Needs-Assessment-Report_Final.pdf. Accessed March 2021.

3. Kangovi S, Mitra N, Grande D, Huo H, Smith RA, Long JA. Community health worker support for disadvantaged patients with multiple chronic diseases: a randomized clinical trial. Am J Public Health. 2017. https://doi. org/10.2105/AJPH.2017.303985.

4. Ingram M, Doubleday K, Bell ML, Lohr A, Murrieta L, Velasco M, et al. Community health worker impact on chronic disease outcomes within primary care examined using electronic health records. Am J Public Health. 2017. https://doi.org/10.2105/AJPH.2017.303934.

5. Kangovi SM, Mitra N, Grande D, Long JA, Asch DA. Evidence-based community health worker program addresses unmet social needs and generates positive return on investment. Health Aff. 2020. https://doi.org/ 10.1377/hlthaff.2019.00981.

6. Cacal SL. Legislative definitions of community health workers: examples from other states to inform Hawai'i. Hawaii J Med Public Health. 2019;78(Suppl 1):23-9.
7. National Academy for State Health Policy. State community health worker models. https://www.nashp.org/state-community-health-workermodels/. Accessed March 2021.

8. State of Utah Department of Technology Services. Long-term occupation projections (2018-2028). https://projectionscentral.org/Projections/ LongTerm. Accessed March 2021.

9. O*NET. Indiana wages for community health workers. https://www.oneto nline.org/link/localwages/21-1094.00?st=IN\&g=Go. Accessed March 2021.

10. Association of State and Territorial Health Officials. Community health workers (CHWs) training/certification standards. https://www.astho.org/ Public-Policy/Public-Health-Law/Scope-of-Practice/CHW-CertificationStandards/. Accessed March 2021.

11. Shearer C, Shah L, Muro M. Advancing opportunity in Central Indiana. https://www.brookings.edu/research/advancing-opportunity-in-centr al-indiana/. Accessed March 2021.

12. Stange KC, Crabtree BF, Miller WL. Publishing multimethod research. Ann Fam Med. 2006;4:292-4.

13. QSR International Pty Ltd. NVivo (Version 12). https://www.qsrinterna tional.com/nvivo-qualitative-data-analysis-software/home. Accessed January 2021.

14. Braun V, Clarke V. Using thematic analysis in psychology. Qual Res Psychol. 2006. https://doi.org/10.1191/1478088706qp063oa.

15. Patton M. Qualitative research and evaluation methods. 4th ed: Sage; 2015.

16. Creswell JW, Poth CN. Qualitative inquiry \& research design: choosing five approaches. 4th ed: Sage.; 2018.

17. Bradley EH, Curry LA, Devers KJ. Qualitative data analysis for health services research: developing taxonomy, themes, and theory. Health Serv Res. 2007. https://doi.org/10.1111/j.1475-6773.2006.00684.X.

18. Bazeley P. The contribution of computer software to integrating qualitative and quantitative data analysis. Res Sch. 2006;13:64-74.

19. Greene JC, Caracelli VJ, Graham WF. Toward a conceptual framework for mixed-method evaluation designs. EEPA. 1989. https://doi.org/10.3102/ 01623737011003255.

20. Anderson C. Presenting and evaluating qualitative research. Am J Pharm Educ. 2010. https://doi.org/10.5688/aj7408141.

21. Kok MC, Broerse JEW, Theobald S, Ormel H, Dieleman M, Taegtmeyer M. Performance of community health workers: situating their intermediary position within complex adaptive health systems. Hum Resour Health. 2017. https://doi.org/10.1186/s12960-017-0234-z.

22. Malcarney M, Pittman P, Quigley L, Horton K, Seiler N. The changing roles of community health workers. Health Serv Res. 2017. https://doi.org/10. 1111/1475-6773.12657.

23. The community health worker core consensus project. https://www. c3project.org/about. Accessed Apr 2021.

24. Sabo S, Allen CG, Sutkowi K, Wennerstrom A. Community health workers in the United States: challenges in identifying, surveying, and supporting the workforce. Am J Public Health. 2017. https://doi.org/10.2105/AJPH. 2017.304096.

25. Covert HA, Sherman M, Miner K, Lichtveld M. Core competencies and a workforce framework for community health workers: a model for advancing the profession. Am J Public Health. 2019. https://doi.org/10.2105/ AJPH.2018.304737.

26. Ingram M, Sabo S, Redondo F, Soto Y, Russell K, Carter H, et al. Establishing voluntary certification of community health workers in Arizona: a policy case study of building a unified workforce. Hum Resour Health. 2020. https://doi.org/10.1186/s12960-020-00487-7.

27. Kangovi S, Mitra N, Grande D, White ML, McCollum S, Sellman J, et al. Patient-centered community health worker intervention to improve posthospital outcomes: a randomized clinical trial. JAMA Intern Med. 2014;174(4):535-43. https://doi.org/10.1001/jamainternmed.2013.14327.

28. Parker EA, Israel BA, Robins TG, Mentz G, Lin X, Brakefield-Caldwll W, et al. Evaluation of community action against asthma: a community health worker intervention to improve children's asthma-related health by reducing household environmental triggers for asthma. Health Educ Behav. 2008;35(3):376-95. https://doi.org/10.1177/1090198106290622.

29. Wennerstrom A, Vannoy SD, Allen CE, Meyers D, O'Toole E, Wells KB, et al. Community-based participatory development of a community health worker mental health outreach role to extend collaborative care in postkatrina new Orleans. Ethn Dis. 2011;21(3 suppl 1):S1-45-51. 
30. Spencer MS, Rosland A-M, Kieffer EC, Sinco BR, Valerio M, Palmisano G, et al. Effectiveness of a community health worker intervention among African American and Latino adults with type 2 diabetes: a randomized controlled trial. Am J Public Health. 2011;101(12):2253-60. https://doi. org/10.2105/AJPH.2010.300106.

31. Kenya S, Jones J, Arheart K, Kobetz E, Chida N, Baer S, et al. Using community health workers to improve clinical outcomes among people living with HIV: a randomized controlled trial. AIDS Behav. 2013;17(9):2927-34. https://doi.org/10.1007/s10461-013-0440-1.

32. Ingram M, Schachter KA, Sabo SJ, Reinschmidt KM, Gomez S, Guernsey De Zapien J, et al. A community health worker intervention to address the social determinants of health through policy change. J Prim Prev. 2014;35(2):119-23. https://doi.org/10.1007/s10935-013-0335-y.

33. The National Association of Community Health Workers (2021). CHW document resource center. NACHW. https://nachw.org/chw-documentresource-center/. Accessed May 2021.

34. Mehra R, Boyd LM, Lewis JB, Cunningham SD. Considerations for building sustainable community health worker programs to improve maternal health. JPC. 2020. https://doi.org/10.1177/2150132720953673.

35. Ibe CA, Wilson LM, Brodine J, Monroe D, Boonyasai RT, Meza B, Tschudy MM, McArthur K, Robinson KA. Impact of community health worker certification on workforce and service delivery for asthma and other selected chronic diseases. Agency for Healthcare Research and Quality http:// www.ncbi.nlm.nih.gov/books/NBK555582/. Accessed April 2021.

36. Center for Disease Control and Prevention. CDC newsroom. https://www. cdc.gov/media/releases/2021/p0325-community-healthworkers-suppo rt.htm|\#: :text=The\%20Centers\%20for\%20Disease\%20Control\%2C\% 20technical\%20assistance\%2C\%20and\%20evaluation. Accessed April 2021.

37. Medium. The Biden plan for mobilizing American talent and heart to create a 21 st century caregiving and education workforce. https://medium. com/@JoeBiden/the-biden-plan-for-mobilizing-american-talent-andheart-to-create-a-21st-century-caregiving-and-af5ba2a2dfeb. Accessed April 2021.

38. Kangovi S, O'Kane M. Community health workers: developing standards to support these frontline workers during the pandemic and beyond. 2020. https://www.milbank.org/2020/05/community-health-workersdeveloping-standards-support/. Accessed April 2021.

\section{Publisher's Note}

Springer Nature remains neutral with regard to jurisdictional claims in published maps and institutional affiliations.

Ready to submit your research? Choose BMC and benefit from:

- fast, convenient online submission

- thorough peer review by experienced researchers in your field

- rapid publication on acceptance

- support for research data, including large and complex data types

- gold Open Access which fosters wider collaboration and increased citations

- maximum visibility for your research: over 100M website views per year

At BMC, research is always in progress.

Learn more biomedcentral.com/submissions 